\title{
DECOLONISING THE POSTGRADUATE DIPLOMA IN HIGHER EDUCATION CURRICULUM AT ONE UNIVERSITY OF TECHNOLOGY IN SOUTH AFRICA
}

\author{
R. S. Lebelo* \\ e-mail: sollyl@vut.ac.za / https://orcid.org/0000-0002-8051-1569
}

\section{K. C. Moloi}

Islamic Studies Department

Madina Institute SA

Cape Town, South Africa

e-mail: khadijah.moloi@madinainstitute.ac.za / http://orcid.org/0000-0003-1913-1206

\section{C. Chitumwa*}

e-mail: chrisc@vut.ac.za / http://orcid.org/0000-0002-9084-8376

*Education Department

Vaal University of Technology

Vanderbijlpark, South Africa

\section{ABSTRACT}

The aim of this theoretical article is to explain efforts at decolonising the Postgraduate Diploma in Higher Education (PGDHE) curriculum at a university of technology (UoT) in South Africa. The main source of information was collected through relevant secondary data. The cost of continuing with Western knowledge organisation in the PGDHE programme destroys and undervalues African intellectualism, culture and literature, while imposing colonial language through prescribed texts. We argue that a clear understanding of decolonisation of the curriculum is necessary, to avoid the risk of implementing changes that will result in superficial alterations, rather than an inclusive curriculum that accentuates African intellectualism. The article recommends that a discourse around decolonisation should be sustained at all levels of the institution in re-thinking and re-evaluating the modules offered in the PGDHE programme to ensure they become more inclusive.

Keywords: decolonisation, curriculum, indigeneity, PGDHE programme, university of technology

\section{INTRODUCTION}

The PGDHE is a generic programme that is offered in most higher education institutions nationally and globally. The process of deciding on the curriculum content in a programme is 
a complex process because of contextual factors that include political, social and economic aspects. The subjects taught in the PGDHE at the UoT are: (i) Learning facilitation in higher education (policy and practice); (ii) Innovative student learning in context; (iii) Module planning and materials development; (iv) Leadership and management in higher education; (v) e-Learning in higher education; (vi) Assessment in higher education; (vii) Professional development as researcher; and (viii) the History of transformation of higher education in South Africa. The PGDHE programme is offered within one of the four faculties at one South African UoT, which was previously a technikon and served white students only until the year 2009, when it gained the status of a university with black students comprising almost 99 per cent of the student cohort. The Faculty of Human Sciences is one of the four faculties in the university. It comprises five departments, namely communication, education, legal studies, tourism and hospitality, and visual arts. The context of this article is framed within the education department in the Faculty of Human Sciences at the institution. A gap in the course offerings exists within the institution and in the Faculty of Human Sciences because disciplines such as the political sciences, African philosophy, sociology of education and Indigenous Knowledge Systems (IKS) are not offered. The absence of these disciplines makes decolonisation of the PGDHE curriculum an overly complex process.

\section{PROBLEM STATEMENT}

The problem that this study explores is decolonising the PGDHE curriculum at one university of technology in South Africa. We believe that a decolonised PGDHE programme would integrate the African perspectives in the current Western content that is being taught. However, Muldoon $(2019,1)$ argues that, "four years after the Rhodes Must Fall, protest in South Africa, the campaign for decolonising the curriculum still faces scepticism and resistance" at institutions of higher education. A study by Ammon $(2019,54)$ reveals that the University of the Free State, for example, appears to be taking an approach to decolonising the university curricula that is primarily concerned with adding on to a curriculum or placing Africa at the centre. Ammon argues that this approach risks implementing changes that will result in superficial alterations, instead of seeing a curriculum as a strand influenced by many other equally important issues, which indirectly could assist in decolonising it. The cost of continuing with Western knowledge in the PGDHE programme destroys and undervalues the African intellectual scholarship, culture and literature, while imposing colonial language through prescribed texts (Musitha and Mafukata 2018, 1). Decolonisation of the curriculum should create shared and negotiated understandings and practices and empower the underrepresented and undervalued while knowledge is being generated and disseminated (Nyathi 2017, 1). For 
Fanon (1963) "the violence with which the supremacy of white values is affirmed and the aggressiveness which has permeated the victory of these values over the ways of life and of thought of the native mean that, in revenge, the native laughs in mockery when Western values are mentioned in front of him". Based on the problem stated, the research questions are:

- What is the decolonisation of the curriculum?

- Why is it important to decolonise the PGDHE curriculum?

- Which aspects of the PGDHE curriculum can be decolonised?

\section{THEORETICAL FRAMEWORK AND LITERATURE REVIEW}

Numerous frameworks on how to decolonise curricula have been suggested from the literature. For this article, the Indigenous Knowledge Systems (IKSs) provides a theoretical framework for us to grasp what decolonisation means and how we could conceptualise decolonising the PGDHE curriculum. Decolonisation of the PGDHE curriculum is predicated on the fundamental premise that IKSs have an important contribution to make to socioeconomic growth and sustainable development in South Africa (Moos, Struwig, and Roberts 2009, 1). IKSs are defined by Tharakan $(2017,1)$ "as knowledge developed within indigenous societies, independent of and prior to the advent of modern scientific knowledge”. Kaya and Seleti (2013, 30) argue that the integration of African Indigenous Knowledge Systems (AIKSs) into the higher educational system could improve its relevance because AIKSs provides a holistic, community-based nature and approach to higher education. For Kaya and Seleti, AIKS provides a theoretical framework of knowledge that can guide the integration process in decolonising the curriculum. Odora-Hoppers $(2017,4)$ suggests that,

\footnotetext{
"African societies have had superior philosophies that engender a sense of solidarity and responsibility to others. At the same time the loss of cultural reference points that is contributing to the fundamental dislocation in higher education, can be traced to the efficiency with which colonialism at the political, economic, and epistemological levels sought to precisely denigrate all those it considered refractory to its gaze."
}

With reference to decolonisation, Fanon $(1963,102)$ identified in the African context three phases of the evolution of social psychology: (i) resistance and acquiescence; (ii) disturbance and (iii) resolution to fight colonialism. He refers to decolonisation as a historical process. After Friedrich Engels in Europe, he was the first African writer who viewed history as a process and not as a chronological series of dramatic events and personalities. Both Engels and Fanon had written in the tradition of scientific historiography, which was fathered by Ibn Khaldun (1332- 
1406) of Tunisia/Algeria. He advocated the colonised taking conscious control of the historical process of decolonisation and recreating themselves as new human beings. For the colonised people, he said, the most essential value, is first and foremost the land. He urged for the starting of a new history of human beings. He called for new inventions, discoveries, and concepts. He revisited the IKS of combining philosophy and psychology. He speaks frankly of the disillusionment of the masses with post-liberation leaders as the spoilt children of national governments who organise the loot of whatever national resources that exist and refers to it as legal robbery. This means that we should not write politically correct curriculum but a curriculum that integrates African intellectualism.

According to Kia $(2017,312)$, indigenous knowledge occupies an important place in African culture, history and politics, hence its importance in the decolonisation of the curriculum process where indigenous people must rediscover their identity. Considering this, Fanon $(1963,103)$ argues that "Europe has multiplied divisions and opposing groups, has fashioned classes and sometimes even racial prejudices, and has endeavoured by every means to bring about and intensify the stratification of colonised societies". Fanon $(1963,103)$ also argues that: "we must achieve revolutionary socialism all together everywhere, or else one by one we will be defeated by our former masters ... whether he's black, yellow, or white, always the same traits of character: he's a sly-boots, a lazybones, and a thief, who lives on nothing, and who understands only violence". Fanon $(1963,103)$ further argues that "we only become what we are by the radical and deep-seated refusal of that which others have made of us".

The concept of decolonisation is understood by Mackinlay and Barney $(2013,1)$ as a process that takes on different connotations across different settings. According to these scholars, decolonisation reminds them of a historical account of the colonisers, a particular version of postcolonial theory, a way of knowing that rejects the Eurocentrism of the West, a moral imperative for battling the abuses of colonial supremacy, social justice and human rights for indigenous people enslaved and disempowered by imperialism. For Licata $(2012,1)$ colonialism by European colonial powers is associated with diverse practices and justified by different ideologies and it created unprecedented instances of encounters between the original colonised inhabitants, locking them in the most complex traumatic relationship in human history. Le Grange $(2016,2)$ argues that since their establishment, South African universities adopted Western models of academic organisation, which largely discounted and annihilated knowledge of the indigenous people.

According to Muldoon $(2019,1)$ decolonisation of the curriculum is not about eliminating white men from the curriculum, but it "is about challenging long-standing biases and omissions that limit how we understand politics and society", as well as broadening the intellectual vision 
that includes a wider range of perspectives. Broadbent $(2017,1)$ argues that decolonising knowledge or a decolonised curriculum are phrases that are not clearly understood and that the process of coming to understand what decolonisation of knowledge might be, is essential to achieving it - and yet that process is not yet complete. Mgqwashu $(2016,1)$ posits that a curriculum is "more than just the topics covered in a course - it encompasses the attitudes, values, dispositions and world views that get learned, unlearned, relearned, reformed, deconstructed and reconstructed" in the process of decolonising the curriculum. Consequently, decolonisation of the curriculum is not a simple and straightforward process, it requires deliberate effort and reimagination. Maserumule $(2015,2)$ argues that the project of decolonisation is about the state of the mind or mental attitude and the socialisation of the academia.

Although democratic independence in South Africa was achieved in 1994, Western influence did not cease - the colonial experiences linger to permeate the cultures and identities of both previously colonising and colonised people, argues Licata $(2012,1)$. Odora-Hoppers $(2017,1)$ suggests that 1994 should signal the "beginning of a new process of deconstruction and reconstruction of the tenets of pedagogy so that non-European people need no longer feel inferior", thereby, enabling them to participate in the Freire's (1970) "project of naming the world as equals along with the numerous others and, thus, creating an alternative and humancentred vision" for curriculum decolonisation. The recent student protests across universities have demonstrated the need to end the domination of Western epistemological traditions, values, histories and symbols (Molefe 2016, 31; Ammon 2019, 7). Similarly, Shay $(2016,1)$ posits that students took the protests as an opportunity to end the Eurocentric curricula in South African higher education institutions. One of the challenges raised is that South Africa's undergraduate curricula is simply no longer fit for its purpose, argues Shay $(2016,1)$. Molefe $(2016,30)$ makes the point that the slow pace of progress on the decolonisation agenda in the South African higher education system has largely been blamed on lack of focus and willingness to address the status quo. This is so, because according to Maserumule $(2015,1)$ some of the professors in African universities are not willing to dismantle colonial strands within the curriculum because they are a cut from the cloth of Western knowledge, particularly those staff members who are predominately white. Drawing on the definitions and clarifications of decolonisation provided in this introduction, the study seeks to understand how the PGDHE curriculum can be decolonised.

\section{THE NEED FOR DECOLONISATION}

Sehoole and Adeyemo $(2016,1)$ suggest that the post-apartheid government that came into 
power in 1994 inherited an inequitable and unjust higher education system whose expression included preferential access to higher education for whites and limited higher education opportunities for the black majority. As a result, one of the priorities of the African National Congress government was to rectify the disparities of apartheid by adopting strategies that would widen access to higher education for all South Africans and, simultaneously, ensure their success. Macha and Kadakia $(2017,1)$ argue that the "country's education system, in particular, has never fully recovered from the 1953 Bantu education law, which was designed to render the country's majority black population disenfranchised, both from the political system and the economy”. Mzwanga $(2018,1)$ argues that,

"in 2002, a major policy decision was taken via the National Plan on Education to approach transformation of the higher education system in South Africa. Attempts to amend the policy on higher education have not translated into material benefits for most previously-disadvantaged black people in South African society in terms of access, equity and participation in higher education."

According to Mzwanga $(2018,1)$, South Africa, continues to invest a considerable amount in education - as it has ever since the end of apartheid. In 2013, for instance, "19.7 per cent of the country's total budget went to education - a relatively high figure by international standards. However, the ripple effect of the discriminatory higher education system continues, not least on the quality of instruction available from a generation of teachers, themselves educated by a sub-par system." Although numerous issues are discussed in literature on the need to decolonise the curriculum, for the purpose of this article we focus on one issue: transforming socioeconomic conditions.

\section{Transforming socio-economic conditions}

Cornell $(2016,1)$ purports that "modern universities and their staff and students exist in a global economy of knowledge, with a definite geography of production and circulation". This economy, he argues,

"has a hegemonic centre, the knowledge institutions of the global north - not only the famous elite institutions like Harvard and the Sorbonne, but also the mass of universities, databanks and research centres supported by the wealth of European and North American societies. This complex of institutions, as well as producing floods of new knowledge (dominating scientific journals in most disciplines), is the centre of intellectual authority in the mainstream economy".

For Oelofsen $(2015,131)$, another form of neo-colonialism that still impacts on South African universities' curricula is the influence of Western powers on South African politics, economy 
and education, because even though the country has attained political independence, much of the means of production, the economy, language of instruction and the content of the curriculum is largely controlled by the former colonisers. Furthermore, Cornell $(2016,2)$ asserts that the "world economy of knowledge is hegemonic and is built on a vast division of labour, with its roots in imperialism. Cornell further points out that in the knowledge institutions of South Africa, these data have been accumulated, archived, classified, interpreted and turned into the organised forms of knowledge that we now teach as university disciplines."

In light of the above, Gerwel and Karim $(2020,1)$ argue that the self-autonomy of higher education institutions and the commercialisation of higher education seem to have diverted the attention of higher education institutions from the educational needs of our students and the society at large, to how much profit the institutions make. Macha and Kadakia $(2017,1)$ argue that "in 2016, the country's economy grew just 0.3 per cent - the weakest pace of growth in seven years. At the end of the year, the unemployment rate stood at 26.5 per cent overall and was even higher among black youth. As the World Bank notes, the country effectively remains a dual economy with one of the highest inequality rates in the world." Gerwel and Karim (2020, 2) argue that the close linkages between universities, their curricula and the students they produce, as well as the economy, makes the decolonisation of the economics curriculum, for example, more necessary to escape the vicious cycle created by the legacy of the colonial project. The solutions aimed towards decolonising the curriculum include Afrocentricity, inclusivity and a pluralistic approach to the teaching of economics. The huge economic, social and educational inequalities inherited from the past apartheid (segregationist) regime have resulted in half of the country's 59,5 million population, of predominantly black South Africans, living in perpetual poverty despite the achievement of democracy in 1994 (Worldometer 2020, $1)$.

Ebrahim and Masiangoako $(2019,1)$ suggest that around 3.6 million of these poor people live in informal settlements where water, sanitation, secure tenure and access to dignified services remain significant challenges. The level of poverty among these black communities became evident during the Covid-19 lockdown where thousands of them stood in long queues waiting to receive food parcels from the government and other charity organisations. According to Nicolson $(2020,1)$ the University of Johannesburg and the Human Sciences Research Council's Covid-19 Democracy Survey that was released found that 34 per cent of the 3543 people interviewed in South Africa during the lockdown had gone to bed hungry; this figure went up from 28 per cent only a week earlier, reported Nicolson. For Workman (2020, 1) Covid19 has given South Africans an opportunity to develop a truly African curriculum to replace an education system that is more than 100 years old and firmly grounded in the First Industrial 
Revolution. Workman claims that this 100-year-old curriculum has remained moribund for many years.

For Mzwanga $(2018,1)$ socio-economic inequalities deny access and widen participation in higher education of black students from poor and under-represented social backgrounds. In light of this, Macha and Kadakia $(2017,1)$ argue that at the tertiary level, deep divides between the country's top-performing and lowest-level institutions remain, as do overwhelming gaps in the rates of whites and non-whites who obtain tertiary-level degrees. Enrolments in universities has swelled from about a half a million in 1994 to close to 1 million students in 2017, with the majority of the students being Africans. Tjønneland $(2017,1)$ argues that,

"this is a dramatic increase - although the number of students in South Africa's higher education system, in relation to the size of its population (59,3 million), is still far too low compared to other middle-income developing countries. The government plans to increase university enrolment to 1.5 million by 2030 . However, there is continued racial disparity in the student population. Black and female students are under-represented in science, engineering and technology, as well as in business and commerce programmes. White males dominate postgraduate studies. Financing is another major challenge. Students cover - through tuition fees - part of the costs."

However, Tjønneland $(2017,1)$ points out,

\begin{abstract}
"that the biggest challenge in South Africa's higher education is not the issue of fees but continued poor access and exceedingly high dropout rates for those who have entered the system. While there has been an impressive increase in the number of black students, including students from extremely poor households, the proportion of poor black students at South African universities is extremely limited." Tjønneland believes that "free education may serve to harden and widen inequalities".
\end{abstract}

Thus, Gerwel and Karim $(2020,1)$ argue that education in South Africa, particularly tertiary education, has become increasingly vocation based and the notion that one needs a degree to get a job is very prominent among our growing youth population. The stress around getting into tertiary institutions and getting a job is only amplified by the rising youth unemployment rate (currently at $53.7 \%$ ) and this, in turn, causes students to feel more pressured than ever to get qualifications. While there are other options to obtain qualifications, aside from universities, there remains the perception that degrees are the only valid forms of qualification and this has several undesirable economic consequences.

\title{
CHALLENGES OF DECOLINISING THE PGDHE CURRICULUM
}

Universities are responsible for the quality of their core academic functions, namely teaching and learning, research and community engagement. A focus on learning and teaching, with 
emphasis on pedagogic and curriculum renewal to support an engagement with students as knowers and knowledge production, is crucial in a decolonised curriculum. Singh $(2007,114)$ suggests that responsive education alludes to a process of supplementation of existing forms of education, rather than wholesale replacement. The purpose of integrating IKS in the PGDHE curriculum is to strengthen and enhance the quality of teaching and learning and, thereby, contribute to knowledge generation and construction in the classroom.

The debate on how we could decolonise the content of the PGDHE is difficult because we presently do not possess the intellectual legitimacy to decolonise the PGDHE curriculum. As such, we agree with Le Grange $(2016,2)$ that understanding decolonisation is not a laid-back experience but a practise not automatically artless to achieve. Since the advancement from our colonisers' knowledge systems cannot be reversed, the decolonisation of the PGDHE curriculum aims at identifying what content should be included in the curriculum. Furthermore, Gerwel and Karim $(2020,1)$ assert that one possible explanation for the little or no change in the university curricula can be attributed to pragmatic inertia. The contested orientations of the curriculum (Singh 2007, 113) should provide new questions and insights into how the curriculum should be re-written through transformative engagements by African scholars.

Given this complex arrangement of knowledge and interconnectedness of the world, when it comes to decolonisation of our PGDHE curriculum, it is a daunting task because theories used in the modules are of Western origin. Another challenge we face is that the student cohort registered in the programme comes from diverse academic fields, including law, engineering, public relations, tourism, education and management sciences. There is thus no guiding framework within the university to foreground our conceptualisation of decolonisation. Consequently, to decolonise, we believe it would make sense to pilot with one of the eight modules and gradually move into the other areas of the PGDHE programme. For the research module, we draw inspiration from Mertens, Cram, and Chilisa's (2013) works on finding indigenous pathways into social research where decolonised methodologies are employed in research. One of the contributors in their book, Moloi (2013), advocates for the reassertion and rebuilding of indigenous knowledge systems from its roots and principles. She states that she uses indigenous languages to explain some of the concepts in research and involves students in practical activities to provide space and agency for them as co-creators of knowledge (Moloi 2013, 109). The approach to teaching in the PGDHE by Moloi resonates with NdimandeHlongwa, Balfour, Mkhize, and Engelbrech's $(2010,347)$ study which reports that,

"the University of KwaZulu-Natal in South Africa approved its bilingual language policy in 2006 based on the framework of the National Language Policy for Higher Education of 2002. The guiding principles of this policy suggest that the university develops the use of isiZulu (one of the 
eleven South African official languages) as a language of instruction and communication, in line with recommendations of the Ministerial Committee report, which investigated the development of indigenous African languages as media of instruction in higher education."

The question is: Is this enough for decolonising the curriculum? Does this warrant transformation towards decolonisation?

\section{WHAT ROLE MUST THE INSTITUTION PLAY IN PROVIDING AN INSTITUTION- WIDE DECOLONISING CURRICULA APPROACH?}

Engagement through dialogue is more likely to build understanding of how the university could be more socially accountable and improve the quality of the educational experience of students. Mgqwashu $(2016,2)$ claims that universities cannot decolonise the curricula without defining it first. This scholar proposes four ways of approaches to curriculum theory in South Africa to take a holistic approach in decolonisation:

(i) "curriculum as product: certain skills to master and facts to know";

(ii) "curriculum as process: the interaction of teachers, students and knowledge";

(iii) "curriculum as context - contextually shaped"; and

(iv) "curriculum as praxis - practice should not focus exclusively on individuals alone or the group alone. It must explore how both create understandings and practices".

Mgqwashu $(2016,2)$ claims that students' experience in our lecture halls are more than just the topics covered in a programme. Hence, his claim that educational experience "encompasses the attitudes, values, dispositions and world views that get learned, un-learned, re-learned, reformed, deconstructed and reconstructed while studying towards a degree". Cornell $(2016,8-$ 9) holds that,

"if the competencies and knowledge needed in the future are becoming more complex, then the task of university staff and students is becoming harder, not easier. Being competent in multiple forms of knowledge and navigating among them, is a tougher proposition than mastering a single episteme. There is serious work here for educationists and philosophers - disciplines not much valued by neoliberal regimes, but particularly important for the future of universities."

Cornell suggests the following steps that can be taken to decolonise a curriculum:

- "Re-examine the discipline's understanding of itself, de-mythologising its history and bringing to light the global-north perspectives embedded in leading theories, methodologies and forms of publication."

- $\quad$ "Recover and circulate major examples of sociological thought from beyond the metropole, 
both historical and contemporary, thus multiple theoretical resources and challenge familiar boundaries of the discipline."

- $\quad$ "Re-make textbooks and undergraduate course plans to include Southern perspectives and a much greater diversity of content. This has gone slowly; major publishers still focus on northern markets, he contends."

- "Reform the institutional framework of the discipline, for example reduce northern hegemony in conferences and associations, by building south/south links and collaborations and attempt to change the practices of journals."

- $\quad$ "Develop new research agendas based on postcolonial perspectives and social needs across the global south, a process now gradually moving through sub-disciplines (criminology, sociology of education, urban sociology, for example), including reflexivity and research on the global economy of knowledge itself."

As Cornell $(2016,9)$ points out, major curricula "reform can hardly be achieved without greater democratisation of the university as an institution and its relation to the wider society. These problems require sustained discussion and experimentation among broad groups of staff and students, who themselves have the power to make things happen on the ground - who can build courses and programmes." Given that the decolonisation of the curriculum has a political, economic and social strand, as purported by Broadbent $(2017,1)$, there is need for all stakeholders to reach a consensus on how to decolonise the curriculum at the institution. We agree with Mackinlay and Barney $(2013,1)$ who posit that through responsible and reflexive practice, "critical pedagogy illuminates how classroom learning embodies selective values, is entangled with relations of power, entails judgements about what knowledge counts, legitimates specific social relations, defines agency in particular ways and always presupposes a particular notion of the future". Critical pedagogy must be embraced as we rethink decolonisation of the PGDHE curriculum.

\section{IMPLICATIONS ON POLICY AND PRACTICE}

There is a dire need to address the epistemological questions of decolonisation of the curriculum within the PGDHE that is examined in this article. The gap that exists within the institution can be addressed by expanding the curriculum in the faculties of Human Sciences and Management Sciences to include Political Science and Sociology as fields of study. Such a stance may provide the bedrock for the development and nurturing of scholarship in postcolonialism, colonialism, indigenous knowledge systems and decoloniality.

\section{RECOMMENDATIONS}

We recommend that academics, as key players in the curriculum decolonisation agenda, take a 
leading role and not wait for institutional cultures and environments to change. We support Motta's $(2013,88)$ notion that "the process of constructing knowledge needs to be reclaimed and remade as a critical act of opening possibility through developing pedagogies (as method and content) with students". Therefore, there is need to continue to revise our curriculum content and teaching methods so that they can become more inclusive and relevant to the African context.

\section{CONCLUSION}

We argued that South African higher education curricula are still Eurocentric, and that this situation needs to be re-addressed. Curricula decolonisation is a significant strategy to address some of the shortcomings in the curriculum, inequalities in the society and past injustices in the higher education arena. Our experiences with the PGDHE attest to the fact that the agenda to decolonise the curriculum is not an easy process. We are in a dilemma on how much of the curriculum we should decolonise, given that the world has become a big seamless global village and for the marketability of our students internationally. We see profitability in embracing both the decolonisation agenda and internationalisation. On one side, we have a strong desire to decolonise the curriculum and on the other side, we want to internationalise it. Concurrently, we seek ways to minimise the downward thread in enrolments that could come as a result of a radical change in the curriculum. We conclude that the process of decolonisation should be system-wide within the institution, guided by an institution-wide framework that provides direction to all stakeholders.

\section{REFERENCES}

Ammon, L. 2019. "Decolonising the university curriculum in South Africa: A case study of the University of the Free State.” Master's thesis. Linnaeus University, Department for Social Studies. Peace and Development.

Broadbent, A. 2017. "African universities must take a critical view of knowledge and how it's made." https://theconverstaion.com/african-universities-must-take-a-critical-view-of-knowledge-andhow-its-made-77878.

Cornell, R. C. 2016. "Decolonising knowledge, democratising curriculum." https://www.google. co.za/url? $\mathrm{sa}=\mathrm{t} \& \mathrm{rct}=\mathrm{j} \& \mathrm{q}=\& \mathrm{esrc}=\mathrm{s} \&$ source $=$ web $\& \mathrm{~cd}=1 \& \mathrm{cad}=\mathrm{rja} \&$ uact $=8 \& \mathrm{ved}=0$ ahUKEwjuP69 sv_WAhUGuhQKHQmMA7cQFggkMAA\&url=https\%3A\%2F\%2Fwww.uj.ac.za\%2Ffaculties $\%$ 2Fhumanities $\% 2$ Fsociology\%2FPublishingImages\%2FPages\%2FSeminars\%2FRaewyn $\% 252$ 0Connell\%25.

Ebrahim, T. and T. Masiangoako. 2019. "Reflecting on South Africa's socioeconomic progress." https://www.constitutionhill.org.za.

Fanon, F. 1963. The wretched of the earth. New York: Grove Weidenfeld.

Freire, P. 1970. Pedagogy of the oppressed. $30^{\text {th }}$ Edition. New York: The Continuum International Publishing Group. 
Gerwel, H. and S. Karim. 2020. Decolonization of the economics curriculum at South African universities: Using the UCT School of Economics as a case study Department of Agricultural Economics, Stellenbosch University and School of Economics, UCT. file://C:/Users/UserPC/Downloads/essa_3903\%20(1).pdf.

Kaya, H. O. and Y. N. Seleti. 2013. "African indigenous knowledge systems and relevance of higher education in South Africa." The International Education Journal: Comparative Perspectives 12(1): $30-44$.

Kia, T. T. 2017. "Governing principles of indigenous institutions and their role in natural resource management and local resource mobilization: The case of Sidaama, Southern Ethiopia." Indilinga African Journal of Indigenous Knowledge Systems 16(2): 312-328.

Le Grange, L. 2016. "Decolonising the university curriculum." South African Journal of Higher Education 30(1): 1-12.

Licata, L. 2012. Colonialism and postcolonialism: Psychological dimensions. The Encyclopedia of peace psychology. First edition. Edited by Daniel J. Christies. New Jersey: Blackwell Publishing.

Macha, W. and A. Kadakia. 2017. Education in South Africa. Education Systems Profiles. https://wenr.wes.org/2017/05/education-south-africa.

Mackinlay, E. and K. Barney. 2013. Unknown and unknowing possibilities: Transformative learning, social justice and decolonising pedagogy in Indigenous Australian Studies, Elizabeth Mackinlay and Katelyn Barney. https://espace.library.uq.edu.au/data/UQ_334729/OAUQ334729.pdf ?Expires=1518355935\&Signature=FfbNB6A5Stlz1iPIfzyalFQisJEPq4eKZckNs3mMAwElpVP ATJrqR NqO3qb.

Maserumule, M. H. 2015. Why Africa's professors are afraid of colonial education being dismantled. The conversation. https://theconversation.com/why-africas-professors-are-afraid-of-colonialeducation-being-dismantled-50930.

Mertens, D., F. Cram and B. Chilisa. 2013. Indigenous pathways into social research: Voices of a new generation. Walnut Creek: Left Coast Press.

Mgqwashu, E. 2016. Universities can't decolonise the curriculum without defining it first. https://www.defsa.org.za/articles/universities-can't-decolonise.

Molefe, T. O. 2016. "Oppression must fall: South Africa's revolution in theory." World Policy Journal 33(1): 30-37.

Moloi, K. C. 2013. An African narrative: The journey if an indigenous social research in South Africa. In Indigenous pathways into social research: Voices of a new generation, ed. D. M. Mertens; F. Cram and B. Chilisa, 101-122. Walnut Creek: Left Coast Press.

Moos, A., J. Struwig and B. Roberts. 2009. Local is lekker: Indigenous knowledge should be encouraged. South African Social Attitudes Survey. http://www.hsrc.ac.za/en/review/november/local-is-lekker.

Motta, S. C. 2013. "Teaching global and social justice as transgressive spaces of possibility." Antipode 45(1): 80-100.

Muldoon, J. 2019. "Academics: It's time to get behind decolonising the curriculum." The Guardian 20 March 2019. https://www.theguardian.com.

Musitha, M. E. and A. M. Mafukata. 2018. "Crisis of decolonizing education: Curriculum implementation in Limpopo Province of South Africa." Africa's Public Service Delivery 6(1): 118.

Mzwanga, S. T. 2019. "The effects of higher education policy on transformation in post-apartheid South Africa." Cogent Education 6: 1. https://www.tandfonline.com/action/showCitFormats?doi=10. 1080\%2F2331186X.2019.1592737.

Ndimande-Hlongwa, N., R. J. Balfour, N. Mkhize, and C. Engelbrecht. 2010. "Progress and challenges for language policy implementation at the University of KwaZulu-Natal." The Language Learning Journal 38(3): 347-357. 
Nicolson, G. 2020. Coronavirus and lockdown. Hunger numbers: Millions, millions, millions, need food. https://www.dailymaverick.co.za/article/2020-05-08-hunger-numbers-millions-millionsmillions-need-food/\#gsc.tab=0.

Nyathi, N. 2017. Decolonising the curriculum: The good, bad and the plain silly. gsbbusiness review.gsb.uct.ac.za.

Odora-Hoppers, C. 2017. Of sediments and trails in decolonizing the curriculum: A transformative response from an African perspective. Pretoria: Department of Basic Education.

Oelofsen, R. 2015. "Decolonisation of the African mind and intellectual landscape." Phronimon 16(2): $130-146$.

Sehoole, C. and K. S. Adeyemo. 2016. "Access to, and success in, higher education in post-apartheid South Africa: Social justice analysis." JHEA/RESA 14(1):1-18.

Shay, S. 2016. Decolonising the curriculum: It's time for a strategy. https://theconversation.com/ decolonising-the-curriculum-its-time-for-a-strategy-60598.

Singh, M. 2007. Responsive education: Enabling transformative engagements with transitions in global/national imperatives. In Globalizing education. Policies, pedagogies, and politics, ed. M. W. Apple, J. Kenway and M. Singh, Chapter 7, 113-134. New York: Peter Lang.

Tharakan, J. 2017. Indigenous knowledge systems for appropriate technology development. Open Access Peer-reviewed chapter. https://www.intechopen.com/books/indigenous-people/ indigenous-knowledge-systems-for-appropriate-technology-development.

Tjønneland, E. N. 2017. "Crisis at South Africa's universities - what are the implications for future cooperation with Norway?" CMI Brief 16(3) 1: 10.

Workman, M. 2020. Education remodelling: Covid-19 is the catalysts for creating an African curriculum. MAVERICK CITIZEN. www.dailymaverick.co.za.

Worldometer. 2020. South African population. Worldometers.com. https://www.worldometers.info/ world-population/south-africa-population/. 